\title{
Functional Ability and Physical Activity in Hereditary Neuromuscular Diseases
}

\author{
Aristomo Andries ${ }^{\mathrm{a}, \mathrm{b}, *}$, Marleen R. Van Walsem ${ }^{\mathrm{a}, \mathrm{c}, \mathrm{d}}$, Kristin Ørstavik $^{\mathrm{a}, \mathrm{e}}$ and Jan C. Frich ${ }^{\mathrm{b}}$ \\ ${ }^{a}$ Department of Neurology, Oslo University Hospital, Nydalen, Oslo, Norway \\ ${ }^{\mathrm{b}}$ Institute of Health and Society, University of Oslo, Blindern, Oslo, Norway \\ ${ }^{\mathrm{c}}$ Department of Neurohabilitation, Oslo University Hospital, Nydalen, Oslo, Norway \\ ${ }^{\mathrm{d}}$ Research Center for Habilitation and Rehabilitation Services and Models, Institute of Health and Society, \\ University of Oslo, Blindern, Oslo, Norway \\ ${ }^{\mathrm{e}}$ European Reference Network Neuromuscular Diseases (ERN EURO-NMD), Paris, France
}

Pre-press 17 February 2022

Published 6 May 2022

\begin{abstract}
.
Background: Physical activity may help to promote health in patients with Limb-girdle muscular dystrophy (LGMD) and Charcot-Marie-Tooth disease (CMT).

Objective: To investigate associations between functional ability and other variables, with physical activity in people with LGMD and CMT grouped according to the International Classification of Functioning, Disability, and Health (ICF).

Methods: We did a cross-sectional study, recruiting respondents from the Norwegian registry of inherited neuromuscular disorders. We used the Norwegian version of Barthel index of Activities of Daily Living (ADL) to measure functional ability and the International Physical Activity Questionnaire -short form (IPAQ-sf) to classify physical activity. We used multivariable logistic regression analysis to investigate associations between variables.

Results: 145 subjects were recruited (79 with CMT and 66 with LGMD). $55.6 \%$ of the subjects met a minimum recommendation of physical activity. Participants with moderate to severe functional ability were more likely to be physically inactive compared to those with normal functional ability (OR 19.7; 95\% CI 3.1-127.2). Mildly decreased functional ability also showed higher odds of being physically inactive compared to participants with normal functional ability (OR $4.1 ; 95 \%$ CI 1.1-15.6). Higher education was associated with inactivity. Fatigue, participation in physiotherapy, and participation in adapted physical activity programs were not associated with physical activity.

Conclusions: Low functional ability was associated with physical inactivity in both LGMD and CMT. Association between higher education and inactivity might indicate the need to provide more understanding about physical activity benefit in this group.
\end{abstract}

Keywords: Neuromuscular diseases, muscular dystrophies, charcot-marie-tooth disease, exercise, physical functional performance

\section{INTRODUCTION}

People with neuromuscular diseases (NMD) may have difficulties in performing daily life activities [1]. Conditions that affect the peripheral nervous system

*Correspondence to: Aristomo Andries, Tel.: +47 48632091; E-mail: aristomo.andries@medisin.uio.no. and/or muscles contribute to functional limitations, especially for physical activities that involve muscle 
work and the extremities [2, 3]. In everyday life, some limitations in daily life functioning may have negative health effects for people with NMD [1, 4].

Recommendations of physical activity in the general population also apply for people with disabilities, including Limb-girdle Muscular Dystrophy (LGMD) and Charcot-Marie-Tooth disease (CMT) [5-7]. Both LGMD and CMT are among the most prevalent hereditary NMDs in Norway [8]. In the absence of curative treatment for LGMD and CMT, physical activity may prevent decline in physical function and promote health $[9,10]$.

Habitual physical activity is physical exercise and activity performed on a regular basis [11] and includes activities while working and moving between places [12]. Studies on people with disabilities have found that various factors influence a person's physical activity, including lack of awareness and interest, insufficient knowledge of how to exercise, the physical environment, lack of time and difficulties with commuting to exercise facilities [13, 14]. In Norway, environmental factors have been shown to influence physical activity [15].

Lower physical activity has been reported in individuals with NMD compared to healthy controls [16, 17]. Compared to healthy individuals, people with NMD experienced more barriers to be physically active $[16,18]$. These barriers can be attributed to their intrinsic muscle condition, such as more frequent pain and fatigue, or external factors such as support from caregivers and the environmental characteristics [16]. Unfortunate circumstances, such as a pandemic, is one example of external factors that hampered the level of physical activity in persons with CMT [19]. In addition to these factors, people with NMD may experience functional limitations $[1,9,20]$. There is a need for more knowledge of how functional ability influences the habitual physical activity level among persons with NMD and to understand how factors may be associated with the level of physical activity.

The aim of the present study was to investigate associations between variables of functional ability and other relevant clinical and socio-demographic variables with physical activity level in people with LGMD and CMT. We hypothesized to find associations between variables of functional ability, other relevant factors, such as fatigue, and physical activity. Variables included in the present study were grouped in accordance with domains in the International Classification of Functioning, Disability, and Health (ICF) [21].

\section{MATERIALS AND METHODS}

\section{Participants and recruitment}

In this cross-sectional survey, 250 individuals who had given their consent to be contacted for research projects were randomly selected from the Norwegian registry of inherited neuromuscular disorders at The University Hospital of North Norway. Study invitations were sent by postal mail to the residential addresses. All adults aged 18-65 years old, with LGMD or CMT diagnosis were invited. NMD patients who were bed ridden, hospitalized or unable to walk, or underwent surgery within three months prior to answering the survey, were not recruited.

Respondents who agreed to participate in the present study gave their written consent. They responded either electronically or via postal mail. The study data were stored in a protected storage under the University of Oslo's Services for Sensitive Data (TSD). We received ethical approval to conduct this study from The Regional Committee for Medical Health Research Ethics (reference number: 2017/713/ REK Sør-Øst A).

\section{Measures}

\section{Physical activity}

We investigated respondents' self-reported level of physical activity using International Physical Activity Questionnaire short form (IPAQ-sf) [22]. This questionnaire has been used in earlier national surveys [23], including a survey on subjects with disabilities [24]. Based on the IPAQ-sf protocol [25] and the Norwegian Health authority's recommendation of being physically active for at least 150 minutes every week [5], we separated physical activity into two groups: the physically active group and the physically inactive group. The physically active group were respondents who had $\geq 20$ minutes/day of vigorous-intensity activities for 3 days or more, $\geq 30$ minutes/day of moderate-intensity activities and/or walking for 5 days or more, or any activities (walking, moderate, or vigorous-intensity activities) for 5 days or more with $\geq 600$ MET-minutes/week. The physically inactive group were those who had less than 20 minutes/day of vigorous-intensity activities for $<3$ days, less than 30 minutes/day of moderateintensity activities and/or walking for $<5$ days, or any activities for less than 5 days with $<600$ METminutes/week. Only physical activity that lasted for at least 10 minutes was counted in the IPAQ-sf. Physical activity was the dependent variable. 


\section{Functional ability}

As the main variable of interest in this study, we used the Barthel index of Activities of Daily Living (ADL) to measure functional ability [26]. This self-reported scale has been used in Norway [27] and several studies on NMD internationally [28-31]. Based on a similar approach and cut-offs [30, 31], we grouped the participants into three groups of functional ability based on the ADL score: normal functional ability group (score 100), mildly dependent group (score 90-99), and moderate-severely dependent group $($ score $<90)$. We had no participants who were completely dependent and fewer in the severely dependent group $(n=5)$. Subsequently, we decided to combine the moderate with severely dependent into one group. In addition, we recorded the score of the mobility components of Barthel index, namely transfer, mobility and using stairs [32]. These mobility components are likely to be affected in both CMT and LGMD, and we divided respondents into two categories according to their scores: one group with maximum score and one group with a reduced score.

\section{Other measures}

The questions to describe participants' type of assistance were taken from The Need and Provision Complexity Scale (NPCS) gets-version [33]. The NPCS has been used in the Norwegian context to explore the health care needs and provisions of people with Huntington's disease and Myotonic Dystrophy $[34,35]$. Self-perceived physical health and mental health were evaluated with RAND-12 from The Norwegian Institute of Public Health [36]. The score was calculated using its scoring manual with permission from the author Prof. John E. Ware, Jr., PhD (personal communication) [37]. Self-reported fatigue was measured using fatigue severity scale [38]. This scale has been evaluated in the Norwegian population [39].

Different groups of variables were described in accordance with the ICF framework [21]. The variables in the body function and structures domain consisted of functional ability (as described by activity of daily living score and activity of daily living mobility score), and the use of any type of assistance (having personal assistance, assistive device, and adapted housing). The domain environmental factors covered socio-demographic variables on education, civil status, and participants' geographical origin. The personal domain comprised the variables physical and mental health perception, fatigue perception, age, gender, ethnicity, participants' mother tongue, and diagnosis. The domain participation was explained by variables regarding the participants' involvement in an adapted physical training program, having physiotherapy, and being employed.

\section{Data analysis}

We described categorical variables as proportions. We used Kolmogorov-Smirnov and Saphiro-Wilk tests in order to assess whether continuous variables were normally distributed. Variables showing significance $(p<0.05)$ on these tests were considered not normally distributed. For these variables, median and interquartile range (IQR) were calculated. In order to analyse differences between the variables for participants with CMT and LGMD, we used the Chi-square test for categorical variables and the Mann-Whitney $\mathrm{U}$ for continuous variables [40]. Only participants with complete data were reported for each variable.

In 97 participants, data was available for variable functional ability, other factors in ICF domains, and physical activity. We used multivariate logistic regression analyses to investigate associations between variables [40]. We investigated collinearities between variables included in multivariate regression analyses using Spearman's rank orders and variance inflation factor (VIF). Correlation coefficients of more than 0.8 or VIF value more than 10 were considered to have multicollinearity [41-44]. We included statistically significant variables from univariate logistic regression analysis and variables based on clinical assumptions and findings from earlier studies $[18,20,23,45]$ in multivariate analysis. We excluded ADL mobility score due to multicollinearity. Furthermore, the variables personal help, assistive device, and adapted housing were excluded because they had been explained by variable any assistance. Therefore, the following variables were included in the multivariate logistic regression analyses: ADL total score, having any assistance, education, employment, diagnosis, age, gender, and fatigue. We reported the odds ratio (OR) and the goodness of fit (adjusted $\mathrm{R}^{2}$ ) for multivariate logistic regression analyses.

Lastly, we compared if there were differences in study variables between those who were included in the analyses and those who were excluded due to missing data, to identify whether this formed a possible bias to the study results. Throughout the study, significance level was set at $p<0.05$. We used the IBM SPSS statistical software version 26 (Armonk, NY, USA). 


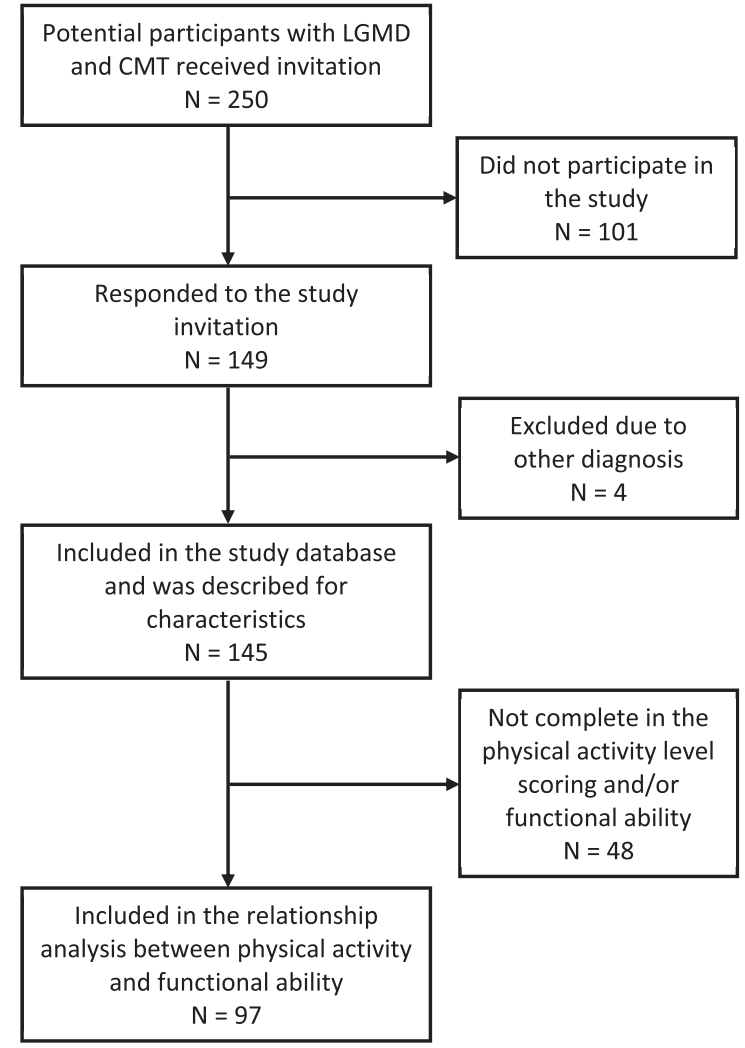

Fig. 1. The flowchart of study participation.

\section{RESULTS}

\section{Study participants' characteristics}

One hundred and forty-nine out of 250 invited individuals, agreed to participate in the study. Four participants were excluded because they were not diagnosed with LGMD or CMT. Of the 145 study participants, 48 participants were not included in the regression analyses investigating the relationship between functional ability and physical activity because they had incomplete scores on variables of functional ability and physical activity level. A remaining 97 respondents were included in logistic regression analyses (Fig. 1).

Subjects who did not partake in the study were younger than those who responded to the study $(p<0.001$ in Mann-Whitney U test). Those who were included in the logistic regression analyses were 2.3 times more likely ( $p=0.041$, in Chi-square test) to report having employment compared to the excluded participants. There was no significant difference for the other independent variables with regard to inclusion in the regression analyses.
The majority of variables did not show any statistically significant difference between the group of people with LGMD and CMT, except for the variables functional ability, use of adapted housing, and employment, with more participants having a normal functional ability score, less adapted housing and more participants being employed in the group of participants with CMT (Table 1).

Most of the respondents scored normal for their functional ability (measured in ADL score): $64 \%$ of them had the maximum total ADL score 100/100. A mild decrease in the total ADL score was observed for $20 \%$ of the study population and only $16 \%$ of the participants were at the moderately to severely dependent level. Considering the mobility components of the Barthel's ADL, more than half of the study participants had maximum scores. Among 108 participants who completed self-reported physical activity level scoring, the majority (56\%) was physically active. From the remaining 48 (44\%) individuals who did not meet the recommendation of minimum physical activity, there were 23 individuals who did not register any physical activity at any intensities that lasted for 10 minutes or more.

\section{Variables associated with the level of physical activity}

In a univariate logistic regression analysis, we found that variables from the body function and structures, environmental, and participation domains were associated with physical activity. These variables were included in multivariate logistic regression analyses (Table 2).

In this model, both ADL total score and education remained significantly associated with physical activity. The chance of being physically inactive was approximately 4 times higher for respondents with mildly dependent ADL compared to participants who had a normal ADL total score (adjusted OR $=4.1$; 95\% CI 1.1-15.6). Respondents who had a moderate to severe ADL score had an almost 20 times increased chance of being physically inactive compared to respondents with a normal ADL score (adjusted $\mathrm{OR}=19.7$; 95\% CI 3.1-127.2). A higher degree of education or education longer than 13 years increased the likelihood for being physically inactive by 3.8 (95\% CI 1.3-11.2) times compared to those with 13 years or less education. The variables diagnosis, age, and self-reported fatigue which were included as covariates showed no significant associations with being physically inactive. The Nagelkerke's $\mathrm{R}^{2}$ was 0.352 . 
Table 1

The study respondents' characteristics regarding body functions and structures, environmental, personal, and participation domains $(n=145)$

\begin{tabular}{|c|c|c|c|}
\hline \multirow[t]{2}{*}{ Variables } & \multicolumn{2}{|c|}{ Diagnosis } & \multirow[t]{2}{*}{ Total } \\
\hline & $\begin{array}{c}\text { CMT } \\
(n=79)\end{array}$ & $\begin{array}{l}\text { LGMD } \\
(n=66)\end{array}$ & \\
\hline \multicolumn{4}{|l|}{ Function and structures } \\
\hline \multicolumn{4}{|l|}{$\mathrm{ADL}$ total score ${ }^{\dagger}, n(\%)$} \\
\hline Normal (100) & $47(68.1)^{*}$ & $36(59.0)^{*}$ & $83(63.8)$ \\
\hline Mildly dependent (90-99) & $16(23.2)^{*}$ & $10(16.4)^{*}$ & $26(20.0)$ \\
\hline Moderate-severely dependent $(<90)$ & $6(8.7)^{*}$ & $15(24.6)^{*}$ & $21(16.2)$ \\
\hline \multicolumn{4}{|l|}{ ADL mobility score,$n(\%)$} \\
\hline Maximum score & $54(77.1)$ & $41(62.1)$ & $95(69.9)$ \\
\hline Reduced & $16(22.9)$ & $25(37.9)$ & $41(30.1)$ \\
\hline \multicolumn{4}{|l|}{ Use of any assistance, $n(\%)$} \\
\hline Yes & $36(45.6)$ & $39(59.1)$ & $75(51.7)$ \\
\hline No & $43(54.4)$ & $27(40.9)$ & $70(48.3)$ \\
\hline \multicolumn{4}{|l|}{ Use of personal assistant, $n(\%)$} \\
\hline Yes & $6(7.6)$ & $12(18.2)$ & $18(12.4)$ \\
\hline No & $73(92.4)$ & $54(81.8)$ & $127(87.6)$ \\
\hline \multicolumn{4}{|l|}{ Use of assistive device ${ }^{\S}, n(\%)$} \\
\hline Yes & $24(30.4)$ & $28(43.1)$ & $52(36.1)$ \\
\hline No & 55 (69.6) & 37 (56.9) & $92(63.9)$ \\
\hline \multicolumn{4}{|l|}{ Use of adapted housing, $n(\%)$} \\
\hline Yes & $20(25.3)^{*}$ & $32(48.5)^{*}$ & $52(35.9)$ \\
\hline No & $59(74.7)^{*}$ & $34(51.5)^{*}$ & $93(64.1)$ \\
\hline \multicolumn{4}{|l|}{ Environmental } \\
\hline \multicolumn{4}{|l|}{ Education, $n(\%)$} \\
\hline College or $>13$ years & $43(54.4)$ & $29(43.9)$ & $72(49.7)$ \\
\hline Up to 13 years & $36(45.6)$ & $37(56.1)$ & $73(50.3)$ \\
\hline \multicolumn{4}{|l|}{ Civil status, $n(\%)$} \\
\hline Married/co-habited & $49(62.0)$ & $45(68.2)$ & $94(64.8)$ \\
\hline Single/divorced/separated & $30(38.0)$ & $21(3$ & $51(35.2)$ \\
\hline \multicolumn{4}{|l|}{ Place of living, $n(\%)$} \\
\hline Place with $\geq 10000$ inhabitants & $48(60.8)$ & $31(47.0)$ & $79(54.5)$ \\
\hline Place with $<10000 \mathrm{inh}$ & $31(39.2)$ & $35(53.0)$ & $66(45.5)$ \\
\hline \multicolumn{4}{|l|}{ Personal } \\
\hline \multicolumn{4}{|l|}{ Gender, $n(\%)$} \\
\hline & $49(62.0)$ & $35(53.0)$ & $84(57.9)$ \\
\hline Male & $30(38.0)$ & $31(4$ & $61(42.1)$ \\
\hline Age in years, median (IQR) & $47(24)$ & $48(20)$ & $48(24)$ \\
\hline \multicolumn{4}{|l|}{ Ethnicity, $n(\%)$} \\
\hline Norwegian/Europ & 75 (94.9) & $66(100.0)$ & $141(97.2)$ \\
\hline Others & $4(5.1)$ & $0(0.0)$ & $4(2.8)$ \\
\hline \multicolumn{4}{|l|}{ Mother tongue, $n(\%)$} \\
\hline Bokmål/Nynorsk & $76(96.2)$ & $65(98.5)$ & $141(97.2)$ \\
\hline Others & $3(3.8)$ & $1(1.5)$ & $4(2.8)$ \\
\hline $\begin{array}{l}\text { Self-perceived physical health scorell, } \\
\text { median (IQR) }\end{array}$ & $32.2(15.3)$ & 30.3 & $30.7(16.1)$ \\
\hline $\begin{array}{l}\text { Self-perceived mental health score } \\
\text { median (IQR) }\end{array}$ & $48.7(18.8)$ & $52.8(17.7)$ & 49.8 \\
\hline Fatigue severity score ${ }^{\S}$, median (IQR) & $5.0(2.2)$ & $5.4(2.2)$ & $5.3(2.3)$ \\
\hline Participation & & & \\
\hline $\begin{array}{l}\text { Adapted physical activity program in } \\
\text { last } 6 \text { months }{ }^{\mathbb{I I}}, n(\%)\end{array}$ & & & \\
\hline Yes & $28(35.4)$ & 17 (26.6) & $45(31.5)$ \\
\hline No & $51(64.6)$ & 47 (73.4) & $98(68.5)$ \\
\hline Physiotherapy in last 6 months $^{\S}, n(\%)$ & & & \\
\hline Yes & $41(52.6)$ & $39(59.1)$ & $80(55.6)$ \\
\hline No & $37(47.4)$ & 27 (40.9) & $64(44.4)$ \\
\hline Employment, $n(\%)$ & & & \\
\hline Employed & $68(86.1)^{*}$ & $46(69.7)^{*}$ & $114(78.6)$ \\
\hline Unemployed/retired & $11(13.9)^{*}$ & $20(30.3)^{*}$ & $31(21.4)$ \\
\hline Physical activity category ${ }^{\#}, n(\%)$ & & & \\
\hline Physically active & $36(62.1)$ & $24(48.0)$ & $60(55.6)$ \\
\hline Physically inactive & $22(37.9)$ & $26(52.0)$ & $48(44.4)$ \\
\hline
\end{tabular}

CMT: Charcot-Marie-Tooth disease; LGMD: Limb-girdle muscular dystrophy; ADL mobility score = mobility, transfer, and stairs components. ${ }^{*} p<0.05$ for the difference between LGMD and CMT diagnoses. ${ }^{\dagger} 130$ participants were included; ${ }^{\ddagger} 136$ participants were included; ${ }^{\S} 144$ participants were included; ${ }^{\mathbb{I}} 143$ participants were included; ${ }^{\# 108}$ participants were included.

\section{DISCUSSION}

We found a significant association between functional ability and physical activity. The ADL total score remained significantly associated with physical activity after adjusting for covariates. This finding suggests that body function and structure are important for the level of physical activity in individuals with LGMD and CMT. Overall, the chance of being physically inactive for both LGMD and CMT was higher for subjects with lower functional ability. Unlike participants with CMT, individuals with LGMD who were moderate-severely dependent had a significantly higher chance of being inactive compared to those with normal functional ability.

Although the ADL mobility score was not included in the multivariate analyses due to collinearity, it showed significant associations with physical activity in the univariate analyses for both patient groups. The LGMD group showed a higher likelihood of being physically inactive. There was also a significant difference in ADL total score between the LGMD and the CMT group. Together, these may indicate more constraints in physical activity due to movement problems in the LGMD group compared to the CMT group. The large muscle groups in the proximal girdle muscles are usually affected in subjects with LGMD [46]. This subsequently creates more difficulties in locomotion in comparison to those with CMT. In CMT, the symptoms usually start distally in the extremities [47] and affect object manipulation and balance rather than locomotion [3].

More than a third of the respondents in our study had decreased functional ability. Several other studies also reported ADL score in NMD using Barthel's index [28, 29, 31]. Contrary to some of the studies that found a lower ADL score in NMD [28, 29], we found that most of the participants in our study had normal ADL scores. Unlike earlier studies that recruited participants in the healthcare facilities, we did a community survey, and our study respondents were likely to be in a better overall health condition than those included in previous studies.

In addition, a normal ADL score in majority of participants did not always imply that they can do all daily tasks without challenges. An earlier study that compared CMT patients with healthy controls found that participants in the CMT group had a lower number of ascending and descending steps; and transitions between sitting and standing. These lower functional indicators were observed even though participants in the CMT group had a high average of 
Table 2

The univariate and multivariate logistic regression analysis for the level of physical activity, being physically inactive

\begin{tabular}{|c|c|c|c|c|}
\hline & \multirow[t]{2}{*}{ Variables } & \multicolumn{2}{|c|}{$\begin{array}{c}\text { Univariate logistic } \\
\text { regression model OR }(95 \% \mathrm{CI})\end{array}$} & \multirow{2}{*}{$\begin{array}{c}\text { Multivariate logistic } \\
\text { regression model } \\
\text { OR }(95 \% \mathrm{CI})\end{array}$} \\
\hline & & $\begin{array}{l}\text { CMT disease } \\
\quad(n=52)\end{array}$ & $\begin{array}{l}\text { LGMD } \\
(n=45)\end{array}$ & \\
\hline \multirow[t]{10}{*}{ Function and structures } & ADL total score & & & \\
\hline & Normal (100) & 1 & 1 & 1 \\
\hline & Mildly dependent (90-99) & 4.14* $(1.00-17.05)$ & $4.75(0.72-31.37)$ & 4.05* $(1.05-15.60)$ \\
\hline & Moderate-severely dependent $(<90)$ & $7.09(0.66-75.89)$ & 26.12* $(2.87-237.55)$ & $19.72 *(3.06-127.18)$ \\
\hline & ADL mobility score & & & \\
\hline & Maximum score & 1 & 1 & - \\
\hline & Reduced & 4.67* (1.04-20.85) & $\mathbf{9 . 8 5}^{*}(2.25-43.18)$ & - \\
\hline & Any assistance & & & \\
\hline & No & 1 & 1 & - \\
\hline & Yes & $1.44(0.47-4.41)$ & 4.96* $(1.39-17.71)$ & $1.11(0.37-3.29)$ \\
\hline \multirow[t]{9}{*}{ Function and structures } & Personal assistant & & & \\
\hline & No & 1 & 1 & - \\
\hline & Yes & $7.06(0.73-68.37)$ & $\infty$ & - \\
\hline & Assistive device & & & \\
\hline & No & 1 & 1 & - \\
\hline & Yes & $0.66(0.19-2.30)$ & 11.88* $(2.68-52.67)$ & - \\
\hline & Adapted housing & & & \\
\hline & No & 1 & 1 & - \\
\hline & Yes & $2.08(0.58-7.43)$ & 4.02* (1.16-13.90) & - \\
\hline \multirow[t]{3}{*}{ Environmental } & Education & & & \\
\hline & Up to 13 years & 1 & 1 & 1 \\
\hline & College or $>13$ years & 4.43* $^{*}(1.29-15.19)$ & $0.91(0.28-2.94)$ & 3.78* (1.28-11.16) \\
\hline \multirow[t]{3}{*}{ Personal } & Diagnosis & & & \\
\hline & CMT & - & - & 1 \\
\hline & LGMD & - & - & $1.09(0.42-2.86)$ \\
\hline \multirow[t]{9}{*}{ Personal } & Gender & & & (1908) \\
\hline & Female & 1 & 1 & 1 \\
\hline & Male & $1.44(0.47-4.41)$ & $0.30(0.09-1.04)$ & $1.29(0.45-3.69)$ \\
\hline & Age & & & \\
\hline & $0-48$ years & 1 & 1 & 1 \\
\hline & $>48$ years & $1.26(0.41-3.84)$ & $1.58(0.48-5.13)$ & $1.26(0.43-3.64)$ \\
\hline & Fatigue severity score & & & \\
\hline & $<4$ & 1 & 1 & 1 \\
\hline & $\geq 4$ & $0.95(0.29-3.10)$ & $1.31(0.38-4.52)$ & $1.06(0.36-3.07)$ \\
\hline \multirow[t]{3}{*}{ Participation } & Employment & & & \\
\hline & Employed & 1 & 1 & 1 \\
\hline & Not employed/retired & 9.38* (1.01-87.28) & $1.59(0.38-6.62)$ & $2.74(0.62-12.10)$ \\
\hline
\end{tabular}

CMT: Charcot-Marie-Tooth disease; LGMD: Limb-Girdle-Muscular Dystrophy; ADL: Activity Daily Living; OR: Odds ratio (OR > 1 increases the chance of being physically inactive). ${ }^{*}$ Significant at $p<0.05 ;{ }^{\infty}$ Unlimited due to null membership for one group in dependent variable for OR calculation; $\mathrm{R}^{2}$ : Nagelkerke's $\mathrm{R}^{2}$.

self-reported ADL score (96 out of 100) [30], suggesting that a decreased functional ability may be present despite of a normal score in a self-reported instrument.

Within the environmental domain, we found an association between education and physical activity. A positive relationship between education and physical activity has been described in earlier studies [48, 49]. Yet, in our study, obtaining a higher educational level or longer duration in education was associated with a higher likelihood of being physically inactive instead of being physically active. Potentially, a higher education leads to occupations or job positions in an office, requiring less physical activity. Since our study did not explore different types of jobs, this assumption requires further investigation.

Regarding variables of the personal domain, other studies have found an association between fatigue and physical activity [20, 50]. Fatigue has been described as the main cause of reduced functional ability in patients with muscular dystrophy as well as with peripheral neuropathy $[50,51]$. Contrary to earlier findings, we found no association between self-reported fatigue and physical activity. 
One explanation for this may be that many subjects with LGMD and CMT have a disease that progresses slowly. In a chronic condition, patients may not observe a significant 'before and after event' as patients with movement problems due to an acute lesion or disease such as brain injury [52]. The gradual functional decline in LGMD and CMT often develops over decades and patients probably adapt to the condition $[53,54]$.

Within the domain of participation, we found no association between attending an adapted physical activity program or physiotherapy with respondent's physical activity. Ideally, participation in the community as an individual or within a group may promote the well-being of individuals with disabilities [55]. Previous studies also showed that adapted training programmes increased the participants' physical and mental condition $[56,57]$. The lack of a relationship found in our study may be because we did not have longitudinal information on these activities. It probably requires several sessions and multiple enquiries to establish an effect of such activities on physical activity [57].

Moreover, unfamiliarity about NMD from the therapist has been found to be one of the reasons that prevented participation in exercise [16]. Without an effective exercise plan adapted to the participants' condition, it is possible that the exercise is suboptimal. The lack of associations between participation in physiotherapy and physical activity might indicate the need to improve specific competence in NMD for physiotherapist.

No significant association was found between employment and physical activity in the multivariate model. We also found that those who were included in the regression analysis had a higher likelihood to have a job compared to those excluded. This selection bias may have contributed to obscure the association between variable employment and physical activity in our sample. A smaller proportion of subjects with a job in the LGMD compared to the CMT group might reflect a higher level of disability in the LGMD group.

Our study suggests that clinicians need to be aware of physical activity in LGMD and CMT patients with a decreased functional ability. These individuals are at a higher risk of being inactive. Patients with NMD are often referred to physiotherapists and rehabilitation centre. Still, we found no association between degree of physical activity and both physiotherapy and an adapted physical activity program. This may indicate that physical activity needs to be continuously encouraged beyond a facility-based program.
Clinicians may consider a community-based physical activity intervention, more integrated in the patients' daily life.

\section{Strength and limitations}

This study had a cross-sectional design. Therefore, we cannot conclude regarding possible causal relationships between the study variables and the respondents' level of physical activity. Although covering the two largest NMD groups in Norway, our study findings may not be generalised to patients with LGMD and CMT who were not in the Norwegian registry of inherited neuromuscular disorders.

We obtained the information about physical activity from all participants within one season period (autumn). Therefore, the differences of physical activity among the study respondents were less likely due to seasonal variation. On the other hand, the respondents of this study came from an older age group. The median age of those who participated in the study differed significantly from those who chose not to. Young age could be associated with being physically more active [48].

Further, we observed a ceiling effect of the ADL score measured by the Barthel's index. Lue and coworkers [31] also found such an effect in their study, particularly for the slowly progressing NMDs. The Barthel index is a general functional ability scale that is not disease specific [3]. We opted to use this scale in our study because our respondents belong to two different NMD diagnoses. In a future study, one may consider a combination of disease specific and general measures of functional ability that are more sensitive to change. Using questionnaires to gather information could also cause a response bias, in that respondents may overstate their level of functional ability and physical activity [42].

Our logistic regression models were conducted with a lower number of participants compared to the overall study respondents. We have analysed the differences between those included in the regression models and those excluded to account for potential selection bias. Nonetheless, a reduced number of subjects in our models has constrained us from including more covariates in the analyses.

Lastly, the multiple logistic regression model only explained $35.2 \%\left(\mathrm{R}^{2}=0.352\right)$ of the variance based on included variables. This implies that other variables not included in this study might play an essential role to determine physical activity. Other factors that were positively correlated with physical activity, such 
as exercise self-efficacy and feeling of enjoyment [18], and factors that hindered physical activity such as fear of falling and lack of motivation [16], may need to be explored. A qualitative approach may be used in future studies to explore other factors that may influence the level of physical activity.

\section{CONCLUSION}

Low functional ability was associated with being physically inactive in subjects with LGMD and CMT. People with LGMD in this study appeared to be more inactive compared with people with CMT. Educational level was negatively associated with physical activity. Contrary to other studies, we did not find significant association in known clinically relevant variables, such as fatigue or participation in physiotherapy and adapted physical activity programs. Future studies would benefit from a longitudinal design, more robust instruments, and the use of quantitative and qualitative methods.

\section{ACKNOWLEDGMENTS}

This study was supported by a grant from Nasjonal Kompetansetjeneste for Sjeldne Diagnoser (NKSD)/Norwegian National Advisory Unit on Rare Disorders. The study used Tjeneste for Sensitive Data (TSD), owned by the University of Oslo (UiO), operated and developed by the TSD service group at the UiO IT-Department (USIT). We are grateful to the University Hospital of North Norway for providing access to the neuromuscular register. Our thanks to Corina Silvia Rueegg, who is a biostatistician at Oslo Centre for Biostatistics and Epidemiology (OCBE), University of Oslo, for her suggestions in the data analysis. We would like to thank all the study participants and their caregivers who have contributed greatly in this study.

\section{CONFLICT OF INTEREST}

The authors have no conflict of interest to report.

\section{AUTHORS' CONTRIBUTIONS}

AA, MvW, JCF contributed to the conception and design of the study. AA contributed to the acquisition of data, analysis and interpretation of data, drafting/revision of manuscript, as well as final approval of the manuscript. $\mathrm{K} \varnothing, \mathrm{MvW}$ and JCF contributed to the analysis and interpretation of data, revision of manuscript and the final approval of the manuscript. All authors have read and approved the manuscript.

\section{FUNDING}

The study was funded by a grant from the Norwegian National Advisory Unit on Rare Disorders in Norway. The funder had no role in study design, data collection and analysis, decision to publish, or preparation of the manuscript.

\section{REFERENCES}

[1] McDonald CM. Physical activity, health impairments, and disability in neuromuscular disease. Am J Phys Med Rehabil. 2002;81(11):S108-20. doi:10.1097/00002060200211001-00012.

[2] Tawil R, Venance S, editors. Neuromuscular disorders. 1st ed. West Sussex: Wiley; 2011.

[3] Katirji B, Kaminski HJ, Ruff RL, editors. Neuromuscular disorders in clinical practice. 2nd ed. New York (NY): Springer Science+Business Media; 2013.

[4] Havercamp SM, Scandlin D, Roth M. Health disparities among adults with developmental disabilities, adults with other disabilities, and adults not reporting disability in North Carolina. Public Health Rep. 2004;119(4):418-26. doi:10. 1016/j.phr.2004.05.006.

[5] Helsedirektoratet. Anbefalinger om kosthold, ernæring og fysisk aktivitet [Recommendations about diet, nutrition, and physical activity]. IS-2170. Oslo: Helsedirektoratet; 2014.

[6] Foster C. Guidelines for health-enhancing physical activity promotion programmes. Tampere: UKK Institute for Health Promotion Research; 2000.

[7] World Health Organization. Global recommendations on physical activity for health. Geneva: WHO Press; 2010.

[8] Jensen SM, Bindoff L, Rasmussen M, Ørstavik K, Arntzen KA, Brenner E, et al. Norsk register for arvelige og medfødte nevromuskulære sykdommer. Årsrapport for 2016 med plan for forbedringstiltak [Norwegian registry for hereditary and congenital neuromuscular diseases. 2016 annual report and improvement measures]. Troms $\varnothing$ : Universitetssykehuset Nord-Norge; 2017.

[9] Anziska Y, Sternberg A. Exercise in neuromuscular disease. Muscle Nerve. 2013;48(1):3-20. doi:10.1002/mus.23771.

[10] Preisler N, Orngreen MC. Exercise in muscle disorders: what is our current state?. Curr Opin Neurol. 2018;31(5): 610-7. doi:10.1097/WCO.0000000000000597.

[11] Jimenez-Moreno AC, Newman J, Charman SJ, Catt M, Trenell MI, Gorman GS, et al. Measuring habitual physical activity in neuromuscular disorders: a systematic review. J Neuromuscul Dis. 2017;4(1):25-52. doi:10.3233/JND160195

[12] Caspersen CJ, Powell KE, Christenson GM. Physical activity, exercise, and physical fitness: definitions and distinctions for health-related research. Public Health Rep. $1985 ; 100(2): 126$.

[13] Rimmer JH, Rubin SS, Braddock D. Barriers to exercise in African American women with physical disabilities. Arch Phys Med Rehabil. 2000;81(2):182-8. doi:10.1016/ S0003-9993(00)90138-2. 
[14] Rimmer JH, Wang E, Smith D. Barriers associated with exercise and community access for individuals with stroke. J Rehabil Res Dev. 2008;45(2):315-22. doi:10.1682/JRRD. 2007.02.0042.

[15] Solbraa AK, Anderssen SA, Holme IM, Kolle E, Hansen $\mathrm{BH}$, Ashe MC. The built environment correlates of objectively measured physical activity in Norwegian adults: A cross-sectional study. J Sport Health Sci. 2018;7(1):19-26. doi:10.1016/j.jshs.2017.11.002.

[16] Phillips M, Flemming N, Tsintzas K. An exploratory study of physical activity and perceived barriers to exercise in ambulant people with neuromuscular disease compared with unaffected controls. Clin Rehabil. 2009;23(8):746-55. doi:10.1177/0269215509334838.

[17] Ramdharry GM, Pollard AJ, Grant R, Dewar EL, Laurá $\mathrm{M}$, Moore SA, et al. A study of physical activity comparing people with Charcot-Marie-Tooth disease to normal control subjects. Disabil Rehabil. 2017;39(17):1753-8. doi: 10.1080/09638288.2016.1211180.

[18] Anens E, Emtner M, Hellström K. Exploratory study of physical activity in persons with Charcot-MarieTooth disease. Arch Phys Med Rehabil. 2015;96(2):260-8. doi:10.1016/j.apmr.2014.09.013.

[19] Prada V, Hamedani M, Genovese F, Zuppa A, Benedetti L, Bellone E, et al. People with Charcot-Marie-Tooth disease and COVID-19: Impaired physical conditions due to the lockdown. An International cross-sectional survey. Ann Phys Rehabil Med. 2020;63(6):557-59. doi:10.1016/ j.rehab.2020.10.001.

[20] Kalkman JS, Schillings ML, Zwarts MJ, van Engelen BG, Bleijenberg G. The development of a model of fatigue in neuromuscular disorders: a longitudinal study. J Psychosom Res. 2007;62(5):571-9. doi:10.1016/j.jpsychores. 2006.11.014.

[21] World Health Organization. International classification of functioning, disability and health: ICF. Geneva: World Health Organization; 2001.

[22] Craig CL, Marshall AL, Sjöström M, Bauman AE, Booth ML, Ainsworth BE, et al. International physical activity questionnaire: 12-country reliability and validity. Med Sci Sports Exerc. 2003;35(8):1381-95. doi:10.1249/01.MSS. 0000078924.61453.FB.

[23] Hansen BH, Anderssen SA, Steene-Johannessen J, Ekelund U, Nilsen AK, Andersen ID, et al. Fysisk aktivitet og sedat tid blant voksne og eldre i Norge - Nasjonal kartlegging 2014-2015 [Physical activity and sedentary time among adults and elderly in Norway - a nationwide survey 20142015]. IS-2367. Oslo: Helsedirektoratet; 2015.

[24] Saebu M, Sørensen M. Factors associated with physical activity among young adults with a disability. Scand J Med Sci Sports. 2011;21(5):730-8. doi:10.1111/j.16000838.2010.01097.x.

[25] Guidelines for data processing and analysis of the International Physical Activity Questionnaire (IPAQ)-short and long forms [homepage on the internet]. IPAQ Research Committee; 2020 [updated $2020 \mathrm{Feb} 12$; cited $2020 \mathrm{Apr}$ 27]. Available from: https://sites.google.com/site/theipaq/ home

[26] Mahoney FI, Barthel DW. Functional Evaluation: The Barthel Index. Md State Med J. 1965;1461-65.

[27] Hansvik HP, Hedlund M. Effekter av rehabilitering: Forprosjekt [Effects of rehabilitation: a pilot project]. Steinkjer: Høgskolen i Nord-Trøndelag; 2015 [updated 2015 Nov 11; cited 2020 Apr 27]. Available from: https://nordopen. nord.no/nord-xmlui/handle/11250/2360051
[28] Freeman JA, Hobart JC, Playford ED, Undy B, Thompson AJ. Evaluating neurorehabilitation: lessons from routine data collection. J Neurol Neurosurg Psychiatry. 2005;76(5): 723-8. doi:10.1136/jnnp.2004.035956.

[29] Boyer F, Novella JL, Bertaud S, Delmer F, Vesselle B, Etienne JC. Hereditary neuromuscular disease and multicomposite subjective health status: feasibility, internal consistency and test-retest reliability in the French version of the Nottingham Health Profile, the ISPN. Clin Rehabil. 2005;19(6):644-53. doi:10.1191/0269215505cr858oa.

[30] Menotti F, Laudani L, Damiani A, Macaluso A. Amount and intensity of daily living activities in Charcot-Marie-Tooth 1A patients. Brain Behav. 2014;4(1):14-20. doi:10.1002/ brb3.187.

[31] Lue YJ, Lin RF, Chen SS, Lu YM. Measurement of the functional status of patients with different types of muscular dystrophy. Kaohsiung J Med Sci. 2009;25(6):325-33. doi: 10.1016/S1607-551X(09)70523-6.

[32] Wade DT. Measurement in neurological rehabilitation. Curr Opin Neurol Neurosurg. 1992;5(5):682-6.

[33] Turner-Stokes L, McCrone P, Jackson DM, Siegert RJ. The Needs and Provision Complexity Scale: a multicentre prospective cohort analysis of met and unmet needs and their cost implications for patients with complex neurological disability. BMJ Open. 2013;3(2):e002353. doi:10.1136/ bmjopen-2012-002353.

[34] van Walsem MR, Howe EI, Iversen K, Frich JC, Andelic $\mathrm{N}$. Unmet needs for healthcare and social support services in patients with Huntington's disease: a cross-sectional population-based study. Orphanet J Rare Dis. 2015;10(1): 124. doi:10.1186/s13023-015-0324-8.

[35] Holmøy AK, Johannessen CH, Hope S, van Walsem MR, Aanonsen NO, Hassel B. Uncovering health and social care needs among myotonic dystrophy patients: Utility of the Needs and Provisions Complexity Scale. Acta Neurol Scand. 2020;139(6):526-32. doi:10.1111/ane. 13086.

[36] RAND-12. Nasjonalt Servicemiljø for Medisinske Kvalitetsregistre [homepage on the internet]. Norway: Folkehelseinstituttet; 2018 [updated 2018 Oct 29; cited $2020 \mathrm{Apr}$ 1]. Available from: https://www.kvalitetsregistre.no/sites/ default/files/https-/www.fhi.no/globalassets/dokumenter filer/tema/brukererfaring/norsk-rand-12.pdf

[37] Ware JE, Keller SD, Kosinski M. SF-36 physical and mental health summary scales. Boston (MA): Health Assessment Lab; 1994.

[38] Krupp LB, LaRocca NG, Muir-Nash J, Steinberg AD. The fatigue severity scale: application to patients with multiple sclerosis and systemic lupus erythematosus. Arch Neurol. 1989;46(10):1121-3. doi:10.1001/archneur.1989. 00520460115022 .

[39] Lerdal A, Wahl AK, Rustoen T, Hanestad BR, Moum T. Fatigue in the general population: a translation and test of the psychometric properties of the Norwegian version of the fatigue severity scale. Scand J Public Health. 2005;33(2): 123-30. doi:10.1080/14034940410028406.

[40] Kirkwood BR, Sterne JA. Essential medical statistics. 2nd ed. Oxford (UK): Blackwell Publishing; 2010.

[41] Hauke J, Kossowski T. Comparison of values of Pearson's and Spearman's correlation coefficients on the same sets of data. Qua Geo. 2011;30(2):87-93. doi:10.2478/v10117011-0021-1.

[42] Rzewnicki R, Auweele YV, De Bourdeaudhuij I. Addressing overreporting on the International Physical Activity Questionnaire (IPAQ) telephone survey with a population 
sample. Public Health Nutr. 2003;6(3):299-305. doi:10. 1079/PHN2002427.

[43] O'brien RM. A caution regarding rules of thumb for variance inflation factors. Qual Quant. 2007;41(5):673-90. doi: 10.1007/s11135-006-9018-6.

[44] Midi H, Sarkar SK, Rana S. Collinearity diagnostics of binary logistic regression model. J Interdiscip Math. 2010; 13(3):253-67.

[45] Hallal PC, Andersen LB, Bull FC, Guthold R, Haskell W, Ekelund U, Lancet Physical Activity Series Working Group. Global physical activity levels: surveillance progress, pitfalls, and prospects. Lancet. 2012;380(9838):247-57. doi: 10.1016/S0140-6736(12)60646-1.

[46] Bergsma A, Janssen MM, Geurts AC, Cup EH, de Groot IJ. Different profiles of upper limb function in four types of neuromuscular disorders. Neuromuscul Disord. 2017;27(12): 1115-22. doi:10.1016/j.nmd.2017.09.003.

[47] Szigeti K, Lupski JR. Charcot-Marie-Tooth disease. Eur J Hum Genet. 2009;17(6):703. doi:10.1038/ejhg.2009.31.

[48] Breivik G, Rafoss K. Fysisk aktivitet; omfang, tilrettelegging og sosial ulikhet-en oppdatering og revisjon [Physical activity; scope, facilitation, and social inequality - an update and revision]. Oslo: Helsedirektoratet. 2017.

[49] Gerovasili V, Agaku IT, Vardavas CI, Filippidis FT. Levels of physical activity among adults 18-64 years old in 28 European countries. Prev Med. 2015;81:87-91. doi: 10.1016/j.ypmed.2015.08.005.

[50] Feasson L, Camdessanché JP, El Mhandi L, Calmels P, Millet GY. Fatigue and neuromuscular diseases. Ann Readapt Med Phys. 2006;49(6):375-84. doi:10.1016/j.annrmp. 2006.04.016.
[51] Angelini C, Tasca E. Fatigue in muscular dystrophies. Neuromuscl Disord. 2012;22:S214-20. doi:10.1016/j.nmd. 2012.10.010.

[52] Self M, Driver S, Stevens L, Warren AM. Physical activity experiences of individuals living with a traumatic brain injury: a qualitative research exploration. Adapt Phys Activ Q. 2013;30(1):20-39. doi:10.1123/apaq.30.1.20

[53] Travlos V, Patman S, Wilson A, Simcock G, Downs J. Quality of life and psychosocial well-being in youth with neuromuscular disorders who are wheelchair users: a systematic review. Arch Phys Med Rehabil. 2017;98(5): 1004-17. doi:10.1016/j.apmr.2016.10.011.

[54] Olson K, Zimka O, Stein E. The nature of fatigue in chronic fatigue syndrome. Qual Health Res. 2015;25(10):1410-22. doi: $10.1177 / 1049732315573954$.

[55] World Health Organization. WHO global disability action plan 2014-2021: Better health for all people with disability. World Health Organization; 2015.

[56] Saebu M, Sørensen M, Halvari H. Motivation for physical activity in young adults with physical disabilities during a rehabilitation stay: a longitudinal test of self-determination theory. J Appl Soc Psychol. 2013;43(3):612-25. doi: 10.1111/j.1559-1816.2013.01042.x.

[57] Preede L, Saebu M, Perrin PB, Nyquist A, Dalen H, BautzHolter E, et al. One-year trajectories of mental and physical functioning during and after rehabilitation among individuals with disabilities. Health Qual Life Outcomes. 2015; 13(1):135. doi:10.1186/s12955-015-0328-z. 